\title{
Impulso e Quantidade de Movimento: Uma proposta de aprendizagem por meio de uma Unidade de Ensino Potencialmente Significativa
}

\author{
Lopes, N. A. ${ }^{1^{*}}$; Orlando, M. T. D. ${ }^{2}$; Bolzan, M. S. ${ }^{3}$
}

\begin{abstract}
1 Programa de Pós-Graduação em Ensino de Física, Instituto Federal do Espírito Santo, Cariacica, ES, Brasil. 2 Departamento de Física e Química, Universidade Federal do Espírito Santo, Vitória, ES, Brasil.

3 Programa de Pós-Graduação em Ensino de Física, Instituto Federal do Espírito Santo, Cariacica, ES, Brasil.
\end{abstract}

*e-mail: natanaguiarlopes@gmail.com

\begin{abstract}
Resumo
No cenário educacional atual muito têm se discutido e realizado pesquisas em ensino de Física que objetiva uma melhor aprendizagem de nossos discentes. É imponente a necessidade de romper com um paradigma apoiado em uma metodologia extremamente tradicional, baseada na premissa que a participação do aprendiz em seu processo de ensino aprendizagem é apenas de ouvinte e receptor de informação. A luz da Teoria da Aprendizagem Significativa de David Ausubel, mais precisamente nas contribuições de Marco Antônio Moreira foi desenvolvida uma Unidade de Ensino Potencialmente Significativa (UEPS), com a utilização de diversas ferramentas e recursos educacionais com a proposta de facilitar a ocorrência de uma aprendizagem significativa do tema: Quantidade de Movimento (Momento Linear), Impulso, e Colisões. Deve-se ressaltar também que algumas atividades foram propostas com um caráter multissensorial, em vista de atender alunos com eventuais deficiências sensoriais, o que também amplia as possibilidades do aprendiz, independente de suas condições sensoriais, alcançar uma aprendizagem mais significativa. A UEPS foi desenvolvida entre os meses de outubro e novembro de 2015 com alunos da 1a Série do ensino médio do curso Técnico em Agropecuária do Instituto Federal do Espírito Santo campus Alegre.
\end{abstract}

Palavras Chave: Aprendizagem Significativa, UEPS, Ensino de Física.

\begin{abstract}
In the current educational scenario much has been discussed and conducted research in teaching physics that aims to better learning of our students. It is imposing the need to break a paradigm supported by an extremely traditional methodology, based on the premise that the participation of the learner in the process of teaching and learning is only listener and receiver of information. The light of the Theory of David Ausubel meaningful learning, more precisely the contributions of Marco Antonio Moreira it developed a Potentially Meaningful Teaching Units (PMTU), with the use of various tools and educational resources with the proposal to facilitate the occurrence of a learning significant theme: Movement amount (Linear Momentum), Impulse, and Collisions. One should also point out that some activities were proposed with a multisensory character, in order to meet students with strong sensory disabilities, which also extends the possibilities of the learner, regardless of their sensory conditions, achieve a more meaningful learning. The LIFO was developed between the months of October and November 2015 with students of the 1st high school course in Agricultural Technical Series of the Federal Institute of Espírito Santo campus Alegre.
\end{abstract}

Keywords : Meaningful Learning, PMTU, Teaching Physics.

\section{Introdução}

Segundo os Parâmetros Curriculares Nacionais (PCN's) [1] o conhecimento em Física tornou-se indispensável à formação da cidadania contemporânea, e deve estar incorporado à cultura como instrumento tecnológico. Espera-se que no ensino médio a Física contribua para uma efetiva aculturação científica, fazendo do aprendiz um cidadão que possa intervir $\mathrm{e}$ participar dos processos sociais como um ser pensante e ativo. Contudo o que se observa nas salas de aula é 
um receio, até mesmo cultural, em estudar física, por ser considerada uma disciplina difícil e sem aplicabilidade no cotidiano, onde a maioria das aulas consiste em decorar fórmulas para aplicar nos exercícios e nas provas.

O ensino denominado tradicional é uma das grandes problemáticas na educação, Segundo Bellucco e Carvalho [2] essa prática utilizada em grande parte das escolas, julga que ensinar e aprender consiste na transmissão direta de conteúdos do docente para os alunos, que muitas vezes são considerados uma "jarra vazia" no qual o professor irá "despejar" conhecimento. Além de não destacar a relevância do conhecimento a ser estudado, o que torna o assunto desinteressante.

Sendo assim, Santos [3] afirma que diante deste cenário é preciso (re) criar, (re) inventar outras formas de ensinar e de aprender a física para nossos alunos. É necessário abrir mão da utilização de quadro e giz em aulas expositivas onde só o professor fala e o aprendiz é considerado apenas um ouvinte, para trazer o aluno para o centro do processo educativo, fazer dele o protagonista na construção do seu conhecimento, criar e propor ferramentas e recursos que abarquem não só um ensino de qualidade como também desperte no aluno a vontade e a disposição para aprender.

A luz da Teoria da aprendizagem significativa de David Ausubel, mais especificadamente na interpretação e contribuição do professor Marco Antonio Moreira, desenvolveu-se uma Unidade de Ensino Potencialmente Significativa (UEPS) com a utilização de diversificadas ferramentas e recursos com a proposta de facilitar a ocorrência de uma aprendizagem significativa.

De acordo com essa teoria, a aprendizagem só é significativa se o aluno for capaz de relacionar 0 conhecimento já presente em seu desenvolvimento cognitivo, com o que ele pretende aprender.

Moreira [4] elucida que este conhecimento pode ser um símbolo, um conceito, uma proposição ou uma imagem, isto é o que David Ausubel chama de Subsunçor ou ideia ancora, que é a ideia que já existe com aluno, que lhe permitirá dar significado ao novo conhecimento a ser aprendido.

Segundo Ausubel [5], se pudéssemos isolar uma única variável como sendo a que mais influencia no desenvolvimento de novas aprendizagens, essa variável seria o conhecimento prévio, ou seja, os subsunçores já existentes na estrutura cognitiva do aluno.

Neste trabalho apresentamos uma unidade de ensino com o tema Impulso e Quantidade de Movimento e avaliamos as condições de aplicação, bem como os resultados obtidos.

Visto que embora as palavras impulso, colisões e até mesmo quantidade de movimento já façam parte do cotidiano de boa parte dos alunos, quando se trata do fenômeno Físico, muitos deles não conseguem visualizar a devida importância e na verdade onde a própria Física está inserida no mundo que os cerca.

A sequencia foi desenvolvida entre os meses de outubro e novembro do ano de 2015 no Instituto Federal do Espírito Santo Campus Alegre.

\section{Metodologia}

As UEPS foram desenvolvidas por Marco Antonio Moreira. Segundo Moreira [6] as UEPS são sequencias de ensino fundamentadas teoricamente na aprendizagem significativa de Ausubel com contribuições de Novak, Gowin e Vernaud, essa metodologia pode estimular a pesquisa aplicada em ensino, aquela voltada diretamente para a sala de aula. Devido a todo o arcabouço no qual está alicerçada, espera-se que este formato de sequência didática seja um facilitador da aprendizagem significativa.

Moreira [6] propõe os 16 princípios de uma UEPS, no qual podemos citar alguns deles como: 0 conhecimento prévio é a variável que influência a aprendizagem significativa; é o aluno que decide de que aprender determinado conteúdo; são as situações problemas que dão sentido ao novo conhecimento; o papel do professor é o de provedor de situaçõesproblema, cuidadosamente selecionadas, de organizador do ensino e mediador da captação de significados de parte do aluno.

Também é proposto por Moreira [6] 8 passos a seguir na construção de uma UEPS, dentre eles podemos citar: definir o tópico específico a ser abordado, identificando seus aspectos declarativos e 
procedimentais; criar/propor situações, discussão, questionário, mapa conceitual, mapa mental, situaçãoproblema, sempre levando em conta o conhecimento prévio do aluno; aumentar o nível de complexidade das situações a medida que se aproxima daquilo que realmente se pretende ensinar; dar seguimento ao processo de diferenciação progressiva retomando as características mais relevantes do conteúdo em questão; avaliar a aprendizagem ao longo de sua implementação da sequencia, registrando tudo que possa ser considerado evidência de aprendizagem significativa do conteúdo trabalhado; por fim, a UEPS somente será considerada exitosa se a avaliação do desempenho dos alunos fornecer evidências de aprendizagem significativa.

Seguindo estes pressupostos foi elaborada uma sequencia de ensino com a utilização de diversificadas ferramentas didáticas que objetivavam facilitar a ocorrência de aprendizagem significativa. Em todas as atividades procurou-se fazer do aluno o centro do processo educativo tornando-o protagonista na construção do seu conhecimento.

A seguir destacamos um pouco de cada ferramenta utilizada ao longo da UEPS.

\begin{tabular}{cl} 
Tabela 1: Atividades desenvolvidas em cada etapa da UEPS. & $\begin{array}{c}\text { Ferramenta didática } \\
\text { Utilizada }\end{array}$ \\
\hline $\begin{array}{c}\text { I- Levantamento de } \\
\text { Conhecimentos prévios }\end{array}$ & $\begin{array}{l}\text { Situações problemas } \\
\text { Peer Instruction } \\
\text { Atividade lúdica }\end{array}$ \\
\hline II- Quantidade de & Experimento Investigativo \\
Movimento & Experimento Investigativo \\
\hline II- Impulso & Vídeo análise \\
Quantidade de Movimento & Situações problemas \\
\hline V- Conservação da & Vídeo análise \\
Quantidade de Movimento & Situações problemas \\
\hline VI- Colisões & Simulação computacional \\
\hline VII- Avaliação & Situações problemas \\
& Avaliação somativa \\
& Questionário de opinião
\end{tabular}

\footnotetext{
2.1 Situações problemas e experimentos por investigação

Optou-se por essa ferramenta visto este tipo de
}

abordagem deve mobilizar o aprendiz, em lugar de sua passividade. Considerando que as crianças trazem consigo para a escola inúmeras concepções sobre o mundo mesmo antes de estudar ciências, a utilização de atividades investigativas surgem como uma proposta que o aprendiz de posiciona como detentor do controle de suas ações a partir de suas concepções prévias.

\subsection{Utilização de Experimentos Multissensoriais}

Nas duas situações os experimentos eram multissensoriais, visto que é compreensível que um estudante com deficiência visual apresente dificuldades de aprendizagem no ensino atual, onde praticamente todas as metodologias de ensino estão fundamentadas e dependentes do sentido visual.

De acordo com Camargo [7] conviver com a diversidade humana, a aceitação das ferramentas individuais, a valorização de cada pessoa e a aprendizagem por intermédio da cooperação são valores éticos que norteiam a inclusão.

Com isso procurou-se proporcionar a qualquer aluno presente no cotidiano escolar ter acesso ao conhecimento, mesmo que os experimentos não tenham sido desenvolvidos exclusivamente para eles,

\subsection{Peer Instruction}

O Peer Instruction é um método desenvolvido por Eric Mazur [8] se baseia no estudo de materiais prévios apresentados pelo professor, e na apresentação de questões conceituais fundamentais para que os alunos respondam e discutam entre si. Após uma breve apresentação oral o professor lança questões conceituais de múltipla escolha e pede aos alunos que votem na resposta correta.

O principal objetivo do IpC é promover o diálogo entre os alunos sobre o conteúdo estudado, e não se recomenda utilizá-la como única ferramenta, e sim associada a outro método de ensino.

\subsection{Uso das Tecnologias de Informação e Comunicação no Ensino de Física.}

Como tecnologia de informação e comunicação, utilizou-se da simulação computacional e a vídeo análise. Neste trabalho foi utilizada uma simulação, do 
site PHET [9] da Universidade do Colorado, para introduzir os tipos de colisões.

Outra ferramenta tecnológica que se pretende explorar neste trabalho é a vídeo análise, que é um processo de análise experimental com a utilização do computador, onde é utilizado um equipamento para captura de imagem (uma webcam, ou um telefone celular) e então se utiliza de um programa computacional para se fazer a análise do experimento. O programa escolhido para a realização do trabalho foi Tracker, por se tratar de um software gratuito, de fácil manipulação e que atende a todas as especificações do trabalho. Segundo Bezerra et.al [10] a utilização do Tracker no ensino médio é promissor por que desperta o interesse do aprendiz, e por conta do seu baixo custo, além de ser importante na realização de atividades experimentais significativas nas aulas de física em um contexto onde essas atividades teriam a função mediadora no ensino dos conteúdos, onde permite que os alunos se tornem agentes centrais e ativos da atividade ao filmar, obterem e tratar os dados.

A figura (1) a seguir, ilustra um fluxograma, que objetiva explicar passo a passo o desenvolvimento da UEPS.

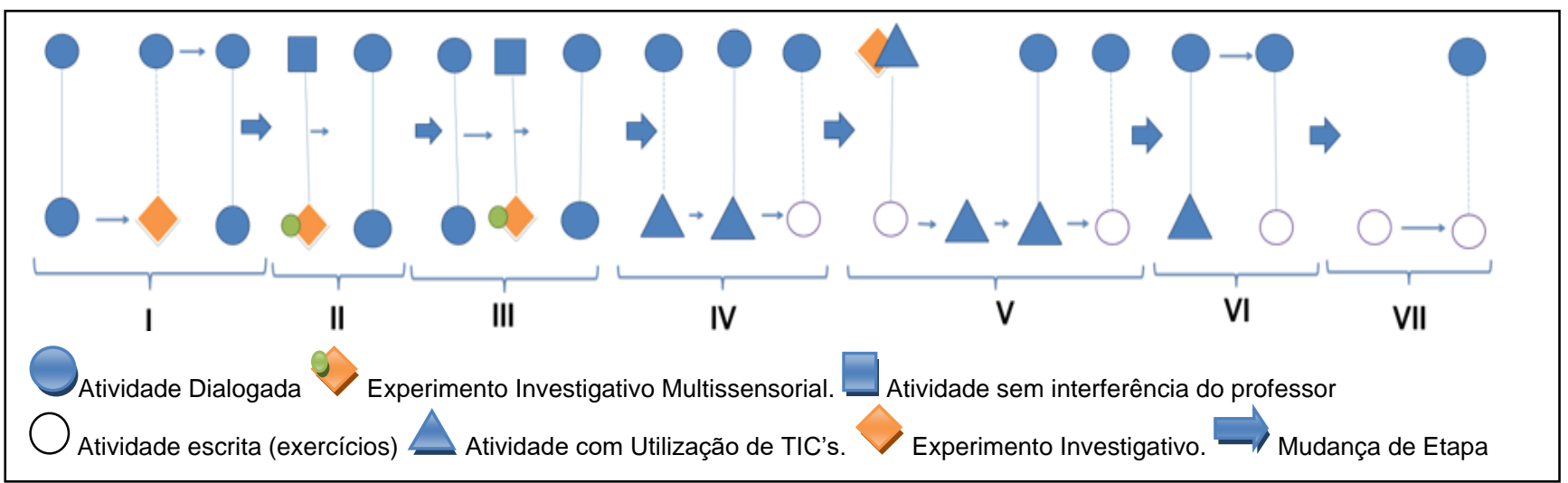

Figura 1- Fluxograma da UEPS. A linha superior do fluxograma ilustra o papel do professor ao longo do desenvolvimento da sequencia, enquanto a linha inferior ilustra o papel do aluno.

Os algarismos romanos indicam cada etapa da sequencia, e na tabela 1 podemos ver quais foram às atividades desenvolvidas em cada uma dessas etapas.

\section{Resultados de Discussão}

A imensa heterogeneidade de fenômenos e seres presentes no ambiente escolar que influenciam direta ou indiretamente no processo de ensino aprendizagem devem ser lavadas em conta no momento de se fazer a análise de uma pesquisa. Por isso optou-se por uma pesquisa qualitativa.

Daniel Augusto Moreira [11] caracteriza esse tipo de pesquisa como sendo relevante o processo, e não o resultado.

Como sugere Moreira [6], a avaliação da UEPS foi realizada ao longo de seu desenvolvimento e houve uma avaliação somativa ao final do processo. Foram utilizadas ao longo da sequência atividades que possivelmente evidenciasse a ocorrência de aprendizagem significativa.
As atividades em grupo foram realizadas em 6 grupos de 6 pessoas, e as atividades realizadas com o Tracker foram realizadas em 9 grupos de 4 pessoas.

$\mathrm{Na}$ etapa I analisando as respostas das situações problemas, percebemos o que já era esperado, que vários dos fenômenos físicos abordados eram explicados a partir de concepções adquiridas no cotidiano. Com o Peer Instruction, obtivemos mais $90 \%$ de respostas corretas após as discussões entre os colegas, que possuíam ideias abarcadas na atividade lúdica, que era um jogo de bola de gude roteirizado, com bolinhas de diferentes tamanhos e massas.

O desenvolvimento conceito de Quantidade de Movimento na etapa II foi finalizado com êxito por todos os grupos sem a necessidade da intervenção do professor, podendo ser considerado a atividade mais exitosa da UEPS.

Quanto ao conceito de impulso, apenas um grupo não conseguiu desenvolver o conceito. Contudo apesar dos demais de uma forma geral conseguirem chegar ao 
"conceito" sem a ajuda do professor, percebeu-se que apesar da "ideia" de impulso estar correta, alguns estavam relacionando 0 impulso diretamente à velocidade. Esta atividade foi discutida em sala de aula, e a partir da fala deles o professor juntamente com a turma trabalhou o conceito detalhadamente.

As atividades para desenvolver os conceitos da etapa IV e $\mathrm{V}$ foram trabalhas primeiramente com vídeos produzidos pelo professor e, análise de situações cotidianas (de forma investigativa). Quanto ao uso do software Tracker, apesar de todos terem feito as filmagens de forma correta em casa, nem todos conseguiram trabalhar com o programa, onde tínhamos problemas mais elaborados para resolver. O sucesso dessas etapas foi alcançado na resolução de situações problemas e nas discussões realizadas em sala de aula.

Quanto às atividades de colisões, os alunos gostaram do simulador e julgaram válido a iniciativa de utiliza-lo devido a praticidade na obtenção de resultados em calcular detalhes que seria muito complicado em um experimento convencional.

Toda essa análise foi feita a partir de relatórios das atividades e textos das situações problemas que o professor recolheu, e através de anotações das falas dos aprendizes, consideradas importantes, em um diário de bordo, tanto os apontamentos positivos quanto os negativos. Também foi analisada através de um questionário de opinião, a aceitação da turma quanto a sequência. Em um aspecto geral aceitação da UEPS foi positiva, em todas as atividades desenvolvidas pode-se observar indícios de aprendizagem significativa. Com exceção de falta de algum estudante esporadicamente, todos os alunos realizaram todas as atividades.

\section{Agradecimentos}

Os autores agradecem a CAPES pelo apoio financeiro, e ao Instituto Federal do Espírito Santo Campus Alegre por permitir a realização do trabalho.

\section{Referências}

[1] BRASIL. Ministério da Educação. Secretaria da Educação Média e Tecnológica. Parâmetros Curriculares Nacionais - Ensino Médio - Parte III Ciências da Natureza, Matemática e suas tecnologias. Disponível

em: <http://portal.mec.gov.br/seb/arquivos/pdf/ciencian.pdf> . Acesso em: 12 abr. 2016.

[2] Bellucco, A. CARVAlho, A.M.P. Cad. Bras. Ens. Fís., v. 31, n. 1, p. 30-59, abr. 2014.

[3] SANTOS, G. A. S. Desenvolvimento de uma Unidade de Ensino Potencialmente Significativa para o Ensino do Conceito de Ondas. Dissertação (Mestrado Profissional em Ensino de Física) - Programa de PósGraduação em Ensino de Física (PPGEnFis) da UFES, Universidade Federal do Espírito Santo, Vitória, 2015.

[4] MOREIRA, M. A. Aprendizagem significativa. Brasília: Ed. Universidade de Brasília, 1999.

[5] AUSUBEL, D. P. A aprendizagem significativa: a teoria de David Ausubel. São Paulo: Moraes, 1982.

[6] MOREIRA, Marco. A. Unidade de Ensino Potencialmente Significativa. Rio Grande do Sul. Disponível em: $<$ http://www.if.ufrgs.br/ moreira/UEPSport.pdf>. Acesso em: mar, 2016.

[7] CAMARGO, E. P. A comunicação como barreira à inclusão de alunos com deficiência visual em aulas de mecânica. Ciênc. educ. 2010, vol.16, n.1. p.258-275. Disponível em: http://www.scielo.br/scielo.php?script=sci_arttext\&pid=S 1516-73132010000100015\&lng=en\&nrm=iso. Acesso em abril de 2016.

[8] ARAUJO, I. S.; MAZUR, E. Cad. Bras. Ens. Fís., v. 30, n. 2, p. 362-284, 2013.

[9] Phet Interactive Simulations, Colorado (USA). Disponível em: https://phet.colorado.edu/pt_BR/. Acesso: 7 abr 2016.

[10] BEZERRA-JR, Arandi Ginane et al. Cad. Bras. de Ens. Fís., v. 29, n. Especial 1, p. 469-490, Jun. 2012.

[11] MOREIRA, D. A. O método fenomenológico na pesquisa. São Paulo: Pioneira Thomson, 2002. 
